\title{
Jacques Lecoq e o Laboratório de Estudos do Movimento (LEM): da escola de arquitetura a um espaço autônomo de cenografia experimental
}

\author{
Ismael Scheffler \\ Universidade Tecnológica Federal do Paraná - UTFPR \\ E-mail: ismaelcuritiba2@gmail.com
}

\section{Resumo}

O presente artigo apresenta aspectos históricos sobre a criação do Laboratório de Estudo do Movimento (LEM) junto à Escola Internacional de Teatro Jacques Lecoq, em 1976, em atividade até os dias de hoje na França. São realizadas considerações sobre a reforma no sistema de ensino de arquitetura na França em decorrência das manifestações estudantis de 1968, contexto que levou Jacques Lecoq a ingressar como professor junto à Unidade Pedagógica de Arquitetura n. 6 (UP6) da Escola Nacional Superior das Belas Artes de Paris, atualmente Escola Nacional Superior de Arquitetura de Paris La Villette, onde lecionou de 1969 a 1987. São apresentadas considerações sobre o arquiteto e cenógrafo Jacques Bosson que mediou o ingresso de Lecoq e a proposta de disciplina experimental que elaboraram juntos. São identificadas as disciplinas que Bosson e Lecoq coordenaram posteriormente, bem como a existência de trabalhos de conclusão de curso de alunos de arquitetura orientados por Lecoq. Por fim, é apresentado o contexto de criação do LEM como um projeto autônomo, da parceria de Lecoq com Krikor Belekian e a contribuição de Pascale Lecoq, ambos arquitetos formados na UP6. Também são apontados aspectos distintos entre a atividade desenvolvida por Lecoq na UP6 e o LEM.

Palavras-chave

Ensino. Cenografia. Teatro francês. História do teatro. Jacques Lecoq.
Abstract

This article presents historical aspects regarding the creation of the Movement Study Laboratory (LEM) at the Jacques Lecoq International School of Theater in 1976, which is still active in France. We present considerations about the reform of the architectural education system in France as a result of the students' demonstrations of 1968, a context that led Jacques Lecoq to join as a teacher at the Pedagogical Unit of Architecture n. 6 (UP6) of the National Superior School of Fine Arts in Paris, now called the National School of Architecture Paris La Villette, where he taught from 1969 to 1987 . We also present considerations concerning architect and set designer Jacques Bosson, who mediated Lecoq's entry and the proposal of an experimental discipline that they planned together. We identify the disciplines that Bosson and Lecoq coordinated afterwards and also the existence of course completion papers written by architecture students advised by Lecoq. Finally, we show the context of the creation of LEM as an autonomous project, from Lecoq's partnership with Krikor Belekian and Pascale Lecoq's contribution, both architects trained at UP6. We also indicate distinct aspects between the activities developed by Lecoq at UP6 and LEM.

Keywords

Teaching. Scenography. French theater. History of theater. Jacques Lecoq. 


\section{Introdução}

Jacques Lecoq (1921-1999) é internacionalmente conhecido como professor de teatro, tendo estabelecido em Paris, em 1956, uma escola para a formação de atores. Outro campo em que atuou também como professor foi na formação de arquitetos, aspecto de sua biografia bastante desconhecido tanto na França quanto no Brasil. De 1969 a 1987, Lecoq, em paralelo a seu trabalho como professor e administrador de sua escola privada de teatro, trabalhou como professor universitário na École Nationale Supérieure d'Architecture de Paris La Villette [Escola Nacional Superior de Arquitetura de Paris La Villette] (ENSAPLV).

Este artigo apresenta o processo de ingresso de Lecoq nesta instituição e tece pontuais considerações sobre a relação com o arquiteto Jacques Bosson. Lecoq e Bosson desenvolveram atividades em parceria e ministraram disciplinas em um eixo de cenografia experimental na ENSAPLV.

Neste artigo, também é apresentado o contexto de fundação do Laboratório de Estudo do Movimento (LEM) como um projeto autônomo da escola de arquitetura e paralalelo à Escola Internacional de Teatro Jacques Lecoq, considerado como um ateliê de cenografia experimental. O LEM, criado em 1976, surgiu da parceria de Lecoq com o arquiteto Krikor Belekian, contanto posteriormente com contribuições de Pascale Lecoq (a partir de 1989).

$O$ ingresso de Lecoq na Escola de Arquitetura e a criação do LEM são decorrentes dos movimentos estudantis de 1968 e da reforma do ensino de arquitetura na França a partir de então.

O presente estudo faz parte de minha pes- quisa de doutorado ${ }^{1}$, sendo aqui revisado. Foi elaborado a partir de diferentes fontes documentais, bibliográficas e de entrevistas com Pascale Lecoq e Krikor Belekian.

As mudanças da formação em Arquitetura na França pós 1968

Jacques Lecoq assumiu, em 1969, como professor na École Nationale Supérieure des Beaux-Arts de Paris [Escola Nacional Superior das Belas Artes de Paris] (ENSBA). Este estabelecimento público de ensino, com prestígio mundial, possuía até 1968 quatro linguagens artísticas compreendidas como "as belas artes": pintura, escultura, gravura e arquitetura.

No ano de 1968, a partir dos movimentos estudantis, políticos e sociais de maio e junho, foram realizadas mudanças profundas na Belas Artes. A pressão estudantil levou à separação da arquitetura das demais artes, sendo criadas então as Unités Pédagogiques d'Architecture [Unidades Pedagógicas de Arquitetura] (UPA). As dez UPAs criadas foram numeradas, sendo seis localizadas em Paris e as demais em outras cidades. Lecoq passou a integrar a Unité Pédagogique d'Architecture $n^{\circ} 6$, conhecida simplesmente como UP6, localizada na Avenida de Flandre, n. 144, no bairro de La Villette, no $19^{\circ}$ arrondissement [distrito] de Paris.

Posteriormente foram criadas outras unidades e, a partir de 2005, todas começaram a ser chamadas de Écoles Nationales Supérieures

1 SCHEFFLER, Ismael. O Laboratório de Estudo do Movimento e o percurso de formação de Jacques Lecoq. 2013. $591 \mathrm{f}$. Tese (Doutorado em Teatro) - Universidade do Estado de Santa Catarina, Programa de Pós-Graduação em Teatro, 2013. Orientação: Prof. Dr. José Ronaldo Faleiro. Apoio: CAPES bolsa sanduíche PSDE. Alguns aspectos históricos já foram publicados preliminarmente nos Anais do VII Congresso da $A B R A C E$, em 2012, estando aqui ampliados. 
d'Architecture [Escolas Nacionais Superiores de Arquitetura] (ENSA). Assim, a UP6 passou a ser a École Nationale Supérieure d'Architecture de Paris La Villette [Escola Nacional Superior de Arquitetura de Paris La Villette] (ENSAPLV).

A partir de 1969, as recém-criadas Unidades Pedagógicas puseram-se a gozar de certa independência para gerir a formação que queriam oferecer. A UP6 se caracterizou por uma grande abertura em especial às ciências humanas e às artes plásticas, oferecendo uma ampla oferta de disciplinas, prezando por um ensino pluridisciplinar e interdisciplinar:

A ENSAPLV é herdeira da Unidade Pedagógica de Arquitetura $\mathrm{n}^{\circ} 6$ fundada em 1969. Nessa condição, é portadora de uma tradição crítica que recusa uma concepção de arquitetura fechada em si mesma, produtora narcisista de "belos" objetos solipsistas. Para ela, a arquitetura é, parafraseando Marcel Mauss, um fenômeno sociocultural total e sua razão de ser, como estabelecimento de ensino superior, é preparar os estudantes para compreender e dominar todos os seus aspectos. [...] Em especial, desde sua origem, ela escolheu não ancorar seu ensino nas práticas profissionais então dominantes na França, mas desenvolveu abordagens novas, especialmente ao articular a reconstrução crítica do ensino da arquitetura à criação plástica, à filosofia, às ciências humanas e sociais como também às ciências e às tecnologias. [...] Ela assegura formações diversificadas que correspondem ao alargamento das formas de intervenção profissional dos arquitetos [...] e de desenvolver a formação para e pela pesquisa. Assim, o projeto pedagógico da escola se distingue pela pluridisciplinaridade e pela interdisciplinaridade dos ensinamentos dispensados, resguardando o ensino do projeto arquitetônico e urbano no centro da formação. (INTRODUTION, 2011).

Sobre a UP6, Pascale Lecoq, arquiteta formada por esta instituição, filha de Jacques
Lecoq, atual diretora da Escola Internacional de Teatro Jacques Lecoq, relembrou: "A UP6 é uma escola especial, por que a UP6 é uma escola muito artística. Nasceu depois de 68, nasceu de todas as pessoas contestadoras que não estavam de acordo com as escolas de arquitetura" (LECOQ, Pascale, 2011).

O ensino, na época, foi estruturado de modo que abrangesse cinco campos: arquitetura; percepção e expressão plástica; construção; ciências exatas; ciências humanas e jurídicas. Além de um quadro comum a todas as unidades pedagógicas de arquitetura, cada unidade poderia propor diferentes disciplinas, o que atribuía certa originalidade de ensino a cada estabelecimento.

\section{O ingresso de Lecoq na Escola de} Arquitetura: relações com Jacques Bosson

Em 1968, naquele momento de grandes transformações para a instituição, Jacques Lecoq foi convidado pelo professor e arquiteto Jacques Bosson (1925-1984) para ministrar uma vivência com os alunos. Krikor Belekian participou dessa atividade:

Eu fiz a Escola de Belas Artes em arquitetura e, em 68, quando houve reviravoltas na pedagogia da arquitetura porque não era aquele o caminho a percorrer. Estávamos em plena revolução, na escola de Belas Artes, em maio de 68. Não havia aulas; então, Jacques Lecoq veio fazer aquela intervenção. Ele tinha vindo fazer um master class, uma só aula, única, sobre o movimento. E todos os alunos que estavam no pátio vieram participar. E ali, fizemos aquela aula em 68 , com 1.200 pessoas. Fizemos um rejeu [rejogo] de uma estação de esqui e depois ele nos fez desenhar. Dessa maneira, o curso 
terminou e em nós ficou algo indelével, que era associar o movimento à arquitetura. (BELEKIAN, 2011).

Após essa bem sucedida experiência, Jacques Lecoq foi convidado para ensinar na Escola de Belas Artes, a partir de 1969.

Pascale Lecoq falou em entrevista sobre essa parceria que se estabeleceu entre o arquiteto Jacques Bosson e seu pai, Jacques Lecoq:

O LEM [Laboratório de Estudo do Movimento]começou realmente na escola de arquitetura. Foi o encontro de meu pai e de um arquiteto que fez com que o LEM existisse; começou numa escola de arquitetura, na UP6. Esse arquiteto convidou meu pai, ele achava que seria interessante fazer os arquitetos se mexerem porque os arquitetos não tinham uma relação com seus corpos, não os conheciam significativamente. Então ele disse a meu pai: "Seria bom que a gente se juntasse" (LECOQ, Pascale, 2011).

Bosson é apontado como o iniciador do ensino de cenografia no seio das escolas de arquitetura na França, a partir de 1965, e serviu de referência para essa prática pedagógica, influenciando outros profissionais (RISACHER, 1984).

Pascale ainda relembrou o contexto do momento:

era em 68, um momento em que se faziam misturas que eram realmente importantes, e as misturas eram: 'Vamos em frente! Colocamos uma pitada de teatro com a arquitetura, colocamos uma pitada de dança com a arquitetura!' Foi assim que foi feito. Então eles desenvolveram uma pedagogia em relação à arquitetura, ao espaço, às formas e ao movimento. (LECOQ, Pascale, 2011).

Dentro desse espírito, Lecoq e Bosson de- senvolveram em colaboração um curso que chamaram de Análise dramática dos espaços. Em setembro de 1969, Lecoq e Bosson participaram da mesa redonda na Bienal de Veneza Ritorno all'espressione fisica dell'attore [Retorno à expressão física do ator] $]^{2}$.

Lá comentaram sobre este novo projeto, como expressou Bosson: "Pela primeira vez, 70 alunos arquitetos, escultores, pintores têm fisicamente, em determinadas situações, experimentado os espaços para tentar defini-lo." (Bosson apud RITORNO, 1969, p. 8). A motivação para se desenvolver uma formação como esta partia da ideia de que "há muito tempo o 'homem' tem sido esquecido, enterrado sob uma tecnocracia monstruosa" (Bosson apud RITORNO, 1969, p. 8), e contra isso, acreditavam ser fundamental propor um trabalho para a formação de arquitetos e urbanistas com uma visão mais humanista, baseada em experiências vividas e não apenas em processos mentais desvinculados de experiências físicas.

A proposta era criar uma disciplina ampla, que dissolvesse as fronteiras entre as linguagens: "Tudo isto presume algumas experiências em comum por meio de disciplinas que se teve o cuidado de não revelar os fatores habituais de cada uma. Escultura, pintura, música, arquitetura, cenografia, urbanismo. Nenhuma disciplina deve ser excluída; seria a rejeição do poder de criação e a abolição do 'dividir para imperar'." (Bosson apud RITORNO, 1969, p. 50).

Neste evento em Veneza, em 1969, a experiência ainda era muito recente, mas vista com grande interesse e esperança. A própria parti-

\footnotetext{
2 As discussões foram publicadas posteriormente (em italiano), em 1970, com o título Ritorno all'espressione fisica dell'attore. Atti della tavola rotonda Internazionale del 19 settembre 1969 [Retorno à expressão física do ator. Ata da mesa redonda internacional de 19 de sentebro de 1969].
} 
cipação de Bosson na mesa redonda sobre o tema da expressão física do ator era resultado desta aproximação (ele mesmo se apresenta na mesa reconhecendo sua presença como insólita, e teve uma participação bastante discreta nas discussões transcritas no documento):

Devemos acrescentar que temos naturalmente encontrado na matemática moderna uma contribuição da linguagem, um corrimão de transmissão entre a nossa linguagem e a de Jacques Lecoq, e que permite vincular a expressão gráfica de dados matemáticos que passam através de um gesto vivido. Trata-se, por hora, dos elementos de uma linguagem comum, mas a experiência é nova demais para falar muito mais; o que sabemos é que isso é possível e que em dois ou três anos ou mais tarde, se poderá criar um espírito verdadeiro coletivo, um denominador comum dentro do grupo que possa nutrir as expressões diferenciadas: gráfica, escrita, construída, rítmica, recitada. E teremos um grupo capaz de construir com transcrições específicas, mas complementares. (Bosson apud RITORNO, 1969, p. 50).

Esta aventura acadêmica, de pesquisa empírica, possuía em sua concepção a ideia de uma linguagem comum, o que sugere afinidade ao conceito do "mimo de fundo" que Lecoq estava amadurecendo nesta época. A vivência corporal do espaço e a relação com as expressões gráficas e construídas já estava presente desde este princípio da interação de Lecoq-Bosson.

Nesta ocasião, Bosson também observou que este empreendimento coletivo era árduo:

Em um primeiro momento, precisamos admitir a confusão devido à mistura de diferentes expressões, o que cria esta confusão maior na qual se coloca tudo junto. Em princípio, isso cria conflitos degenerativos, de incompreensões no nível da palavra, mas se perseverar percebe muito rapidamente que, mesmo se usar uma palavra diferente, isso significa a mesma coisa, se reconhece o comportamento, a respiração, o tônus, o gesto, os signos físicos e até mesmo se na divisão dos componentes que se fará dentro desta equipe, a linguagem torna-se específica na ação, terá sua base comum; é isto que devemos reconstruir antes de tudo. E o nascimento de uma equipe é que dirá. Assim, podemos construir juntos, a partir de uma infra-estrutura repensada em comum, uma estrutura, um gesto, um texto, um ritmo. (Bosson apud RITORNO, 1969, p. 51).

Em entrevista, Belekian falou sobre o momento e a motivação do convite estendido a Lecoq em 1968, da parceria estabelecida e posterior independência do trabalho de ambos logo a seguir:

Jacques Bosson amava muito o teatro. Sua esposa dirigia a Escola Dullin, que era outra escola de teatro muito conhecida, mas essa escola começava a se liquefazer, ela quase não existia mais ${ }^{3}$. Jacques Bosson tentou colaborar com Jacques Lecoq para dar um impulso a sua escola. Ora, Jacques já tinha a sua escola. Então... convidou Jacques Lecoq a lecionar na escola de Belas Artes, e foi assim que a colaboração entre eles nasceu. Mas como Jacques Lecoq era um pesquisador e tinha uma fascinação pela arquitetura e pelas artes, tentou dirigir um pouco a pedagogia. (BELEKIAN, 2011).

Pouco tempo depois de iniciarem a parceria, Bosson e Lecoq desenvolveram atividades distintas na UP6.

\footnotetext{
3 Bosson era casado com a atriz Monique Hermant-Bosson (1922-2017), diretora da Escola de Teatro Charles-Dullin de 1977 a 1997. A Escola de Teatro Charles-Dullin partilhava elementos pedagógicos em comum com a pedagogia de Lecoq (ver SCHEFFLER (2013), a respeito da influência de Dullin sobre a pedagogia de Lecoq).
} 
Disciplinas no campo da cenografia experimental na UP6

Jacques Lecoq afirmou que após trabalhar com os alunos arquitetos de Bosson, levando suas experiências sobre o corpo e o movimento, foi nomeado professor e depois diretor de estudo (LECOQ, 1995), na UP6.

$\mathrm{Na}$ conferência-demonstração Le corps et son espace [O corpo e seu espaço], publicada em janeiro de 1974, pelo Institut de l'Environnement [Instituto do Meio-Ambiente], ele finalizou sua conferência contextualizando-se:

é neste sentido que comecei na Escola de Belas Artes um Laboratório de Estudo do Movimento, com o estudo e a fabricação de formas (arquiteturas portáteis) que permitem apreender o espaço, afim de que os futuros arquitetos conheçam melhor o valor dos espaços que eles constroem sem esquecer que, dentro, os homens vivem em movimento. (LECOQ, 1974, p. 281).

Desta declaração, publicada em janeiro de 1974, podemos supor que já a partir dos primeiros anos de 1970, Lecoq passou a desenvolver um trabalho independente de Bosson na Escola de Arquitetura.

A partir disto, a instituição passou a oferecer uma série de disciplinas diferentes relacionadas ao campo da cenografia encabeçadas por Jacques Bosson e por Jacques Lecoq.

No Centro de Documentação da Escola Nacional Superior de Arquitetura de Paris La Villette, é possível encontrar os anuários Activités d'Enseignement [Atividades de Ensino], documentos da instituição que reúnem informações e o programa de todas as disciplinas oferecidas a cada ano letivo. Os anuários disponíveis que lá se encontram correspondem ao período que inicia com o ano letivo de 1979-1980. Infelizmente o Centro não dispõe dos anuários anteriores, que interessariam também a esta pesquisa, isto é, de 1969 ao primeiro semestre de 1979. (Os responsáveis pelo Centro de Documentação também não souberam informar se durante esse período esses documentos foram feitos).

Tomando as informações que constam no documento Activités d'Enseignement 19811982 [Atividades de Ensino 1981-1982] (UNITÉ, 1981, p. 118, 144 e 153), por exemplo, pode-se encontrar dados sobre as três disciplinas anuais de responsabilidade de Jacques Bosson: Ecologie des espaces [Ecologia dos espaços]; Scénographie [Cenografia]; Architecture mobile [Arquitetura móvel] ${ }^{4}$.

Também é possível encontrar informações sobre as duas disciplinas anuais de responsabilidade de Jacques Lecoq (UNITÉ, 1981, p. 145, 146): Laboratoire d'analyse des mouvements du corps humain et de ses espaces [Laboratório de análise dos movimentos do corpo humano e de seus espaços], posteriormente denomiado como Laboratoire d'Étude

4 A relação entre a escola de arquitetura e da Escola de Tea-
tro Charles-Dullin se estreitou a partir de 1974, no estabele-
cimento de uma parceria. Os espetáculos montados com os
alunos atores da Escola de Teatro Charles-Dullin passaram
a servir como campo de prática cenográfica para os alunos
da disciplina de cenografia do curso de Arquitetura da UP6:
"Mais tarde, é em Les Halles que ela [a Escola Charles-Dullin]
se instala, com a direção de Monique Hermand-Bosson. Com
o marido, Jacques Bosson, arquiteto, ela inicia em 1974 uma
parceria com a escola de arquitetura, que hoje se tornou Es-
cola Nacional Superior de Arquitetura Paris-La Villette UP6.
A cada ano, uma peça, interpretada pelos alunos do terceiro
ano da escola, cuja cenografia é realizada pelos estudantes
de arquitetura, concretiza essa associação." (CHARTRE,
2011 ). Essa parceira permaneceu até 2010 sob a orientação
de Bernard Pigot, ex-aluno da Escola Charles-Dullin (1975-
1977) e do Conservatório Nacional Superior de Arte Dramáti-
ca de Paris, tendo se tornado diretor da Escola Charles-Dullin
de 1998 a 2010 e professor de interpretação, bem como era
professor da Escola de Arquitetura Paris La Villette, onde de-
senvolvia as disciplinas de Cenografia e História do teatro. (CHARTRE, 2011). 
du Mouvement [Laboratório de Estudo do Movimento]; Laboratoire d'étude du mouvement et d'architecture dramatique [Laboratório de estudo do movimento e de arquitetura dramática], referido em anos seguintes como Laboratoire d'Architecture Dramatique [Laboratório de Arquitetura Dramática].

Uma pesquisa documental mais aprofundada precisaria ser feita para se conhecer os pensamentos e práticas pedagógicas de Bosson. Na revista AS - Actualité de la Scénografie [Atualidade da Cenografia], n. 24, de 1984, pode-se encontrar uma homenagem feita a Bosson após seu falecimento ${ }^{5}$ (RISACHER, 1984).

A revista traz algumas citações breves de palavras do próprio Jacques Bosson (as fontes de onde as citações de Bosson foram retiradas não são, contudo, indicadas). Em uma delas, Bosson comentava sobre seu trabalho na UP6: "As experiências que eu dirijo na U.P.A. n.6 nos módulos de 'cenografia' e de 'ecologia dos espaços' liberaram pouco a pouco o lugar que seria suscetível de ser o espaço ideal de pesquisa interdisciplinar para todos aqueles para quem a prioridade é o estudo dramático do homem e de seus espaços" (Bosson apud RISACHER, 1984, p. 53).

Outra citação permite visualisar, mesmo que brevemente, que Bosson e Lecoq possuíam alguns pensamentos afins, como a necessidade de se vivenciar o espaço como forma de aprender/apreender o conceito de espaço: "Não é preciso discorrer sobre o espaço, mas o praticar. Discorrer, é a cabeça. Praticar, é o

5 Essas páginas contêm depoimentos de amigos e ex-alunos, ilustrações de suas principais obras; destacam sua prática docente na UP6 e seu trabalho como arquiteto teatral e cenógrafo. Entre outros projetos de Bosson relacionados ao teatro, encontra-se o projeto da Maison Jean Vilar [Casa Jean Vilar], em Avignon. A Maison Jean Vilar foi criada em 1979, surgindo da parceria da prefeitura de Avignon com a Biblioteca Nacional da França e a Associação Jean Vilar. corpo e a cabeça. O espaço sem o corpo não existe. O espaço sem o corpo é a ideia do espaço. A única ideia para reter é que é preciso praticar o espaço." (RISACHER, 1984, p. 52).

\section{Lecoq como orientador de trabalhos de conclusão de curso}

Como parte do processo de formação dos alunos de arquitetura, estava o desenvolvimento de um projeto final orientado por um dos professores do curso. Destes projetos, podemos encontrar alguns memoriais que apresentam pesquisas que tiveram a orientação de Jacques Lecoq.

A UP6 foi o local de formação acadêmica e profissional de Krikor Belekian (formado em 1972) e Pascale Lecoq (formada em 1987) como arquitetos. Entre os dois pólos (em 1987 Lecoq se aposenta na ENSAPLV), outros quatro trabalhos pertinentes foram encontrados. É possível que existam mais memoriais de diplomação orientados por Jacques Lecoq na UP6 ou que possuam influências indiretas dele. No entanto, devido ao sistema de organização das informações dos arquivos e dos meios de busca, não foi possível realizar, ao menos por ora, um rastreamento preciso nos acervos existentes.

O memorial de conclusão de curso de Krikor Belekian teve orientação de Jacques Lecoq, em 1972, sendo possivelmente a primeira orientação dele. Spectacle d'architectures portables [Espetáculo de arquiteturas portáteis] é considerado como uma pesquisa relevante que deu origem à pedagogia desenvolvida no Laboratório de Estudo do Movimento (LEM), vinculado à escola de Lecoq em 1976, em atividade até os dias de hoje. Na conferência 
publicada em 1974, Lecoq já faz menção às estruturas portáteis.

Figura 1 - Estrutura portátil confeccionada no LEM (2011)

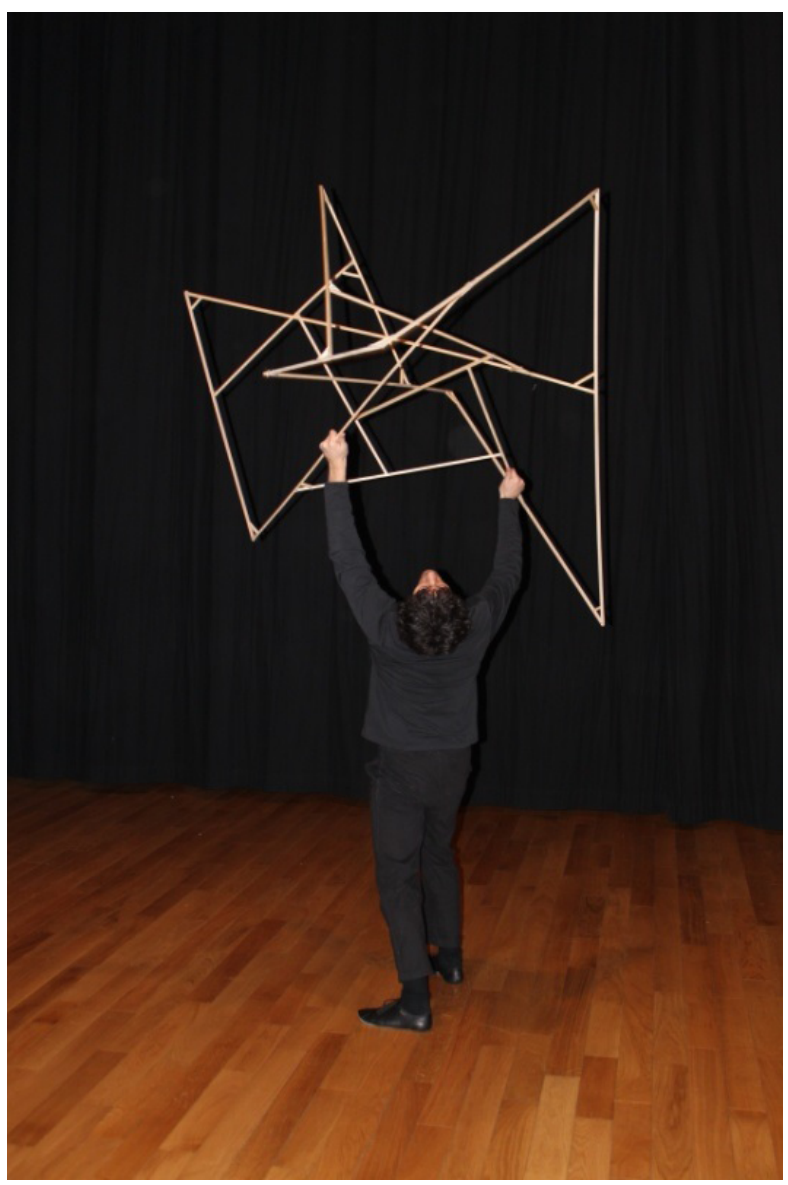

Foto: acervo pessoal

Outro trabalho de diplomação com orientação de Lecoq é de Axelle Le Fur (1977): Recherche pour un habitat du calme [Pesquisa para um habitat da calma]. Da década de 1980, encontrei três memoriais de diplomação: Corps-PI [Corpo-PI], de Severino Rodriguez-Veja (1985); A corps perdu - Spatialisation du "corps" poétique dans l'ouevre de Bernard Noël: 'Extraits du corps' [Apaixonadamente Espacialização do 'corpo' poético na obra de Bernard Noel: 'Extratos do corpo'], de Stéphane Lévy (1987); e Paysage de banlieue [Paisagem da periferia], de Sophie Allard (1987).

Outro trabalho de diplomação que podemos relacionar é de Pascale Lecoq, também de 1987. Embora não tenha sido orientado por Jacques Lecoq, ele está em conceito e prática relacionado a seus princípios de ensino. $O$ trabalho teve orientação do professor de paisagismo Jean-Pierre Le Dantec e teve o título: Une gare et son quartier - les passions et états humains comme thème [Uma estação de trem e seu bairro - as paixões e os estados humanos como tema].

O conteúdo desses trabalhos possui materiais de naturezas diferentes, desde análises teóricas e conceituais a proposições arquitetônicas, incluindo a descrição de exercícios. Uma revisão deles permite vislumbrar alguns aspectos do que consistiram as disciplinas ministradas por Lecoq na época e visualizar a presença de conceitos e práticas. O contato com essa produção acadêmica também permite examinar a bibliografia indicada, o que ajuda a perceber determinados referenciais teóricos e artísticos que construíram o pensamento de Lecoq.

Da Escola de Arquitetura a um projeto autônomo: Krikor Belekian e Pascale Lecoq

Em 1976, a escola de teatro de Lecoq, depois de ocupar diferentes locais para seu funcionamento, finalmente se instalou em sua sede atual, situada na rua do Faubourg Saint-Denis. Lecoq já lecionava na UP6 a cerca de 6 anos e sua escola de teatro completava 20 anos.

Krikor Belekian foi o arquiteto responsável pelas reformas das instalações do antigo centro esportivo de box chamado o "Central". A instalação naquele espaço não apenas libertava a escola das transferências reiteradas de endereço, como havia acontecido nos últimos 
anos, mas também inspirava a seguir em crescimento. Assim, surgiu da parceria entre Belekian e Lecoq um projeto novo e independente, tanto da UP6 quanto da Escola de Teatro:

Ele [o LEM] começou porque tínhamos o desejo de ser independentes. Dependíamos da UP6. Pensamos que abrir um departamento nos permitiria ser muito mais independentes para propulsar mais longe a pedagogia, e nossas pesquisas muito mais livres, fora de um quadro universitário. Éramos Jacques e eu, dois professores, e tínhamos três alunos. (BELEKIAN, 2011).

Jacques Lecoq e Krikor Belekian criaram em sociedade a APEM - Association Pour l'Étude du Mouvement [Associação para o Estudo do Movimento], que é a pessoa jurídica que promove o LEM. A data atribuída a criação do LEM diverge nos materiais publicados por eles. Algus panfletos informam que o LEM foi criado em 1977, mas em outras fontes (LECOQ, 1995; 2010) encontramos a referência ao ano de 1976. É possível que o LEM tenha sido concebido em 1976, data em que a escola se instalou na nova sede e completava 20 anos de existência e suas aulas tenham oficialmente começado em 1977.

Belekian assim definiu o LEM: "O LEM é o departamento cenográfico da escola Jacques Lecoq, autônomo em relação à escola. Quem faz a escola não é obrigado a fazer o LEM e quem faz o LEM não é obrigado a fazer a escola. É um laboratório completamente à parte. Mas há sempre o sopro de Jacques Lecoq no LEM e na escola". (BELEKIAN, 2011).

Se por um lado o trabalho na UP6 nasceu a partir da influência da pedagogia de Lecoq em sua escola de teatro, agora o LEM nascia no seio da escola a partir do trabalho na UP6:
O LEM se desenvolveu até a morte de Jacques Lecoq sempre com uma preocupação de impulsionar para além, de elaborar toda uma trama, toda uma estrutura pedagógica que estava, aliás, mais próxima da escola dos atores, mas que era a ideia de fazer um departamento à parte, consagrado à cenografia vista de uma maneira ampla, não a cenografia aplicada a uma maneira de fazer. Quer dizer, dar os fundamentos do que é o espaço de fato, como eu lhes disse várias vezes. Quando dizemos "espaço", há tudo e nada dentro. Mas como se constrói o espaço cenográfico? Esse é o grande questionamento. Mas para nós, tudo parte do vivo, seja da vida do homem, dos animais, todo ser vivo, e que se estende depois ao jogo teatral. (BELEKIAN, 2011).

O Laboratório de Estudo do Movimento que foi criado junto à escola de teatro não foi uma simples transposição do trabalho já realizado na UP6. Belekian ressaltou isto:

Não era a mesma forma de trabalho. Lá havia dois módulos: o "LEM" e "Arquitetura dramática", que era destinada aos arquitetos, mas era mais pesquisar o drama de arquiteturas limites. Como se constrói uma casa invejosa? orgulhosa? Era aplicado à arquitetura. Então vamos fazer arquiteturas limites ? Não, por que não era construir a casa do orgulho ou da inveja, mas era um pretexto para que o estudante de arquitetura pudesse se aproximar daquele mundo do movimento e da forma, mas através da arquitetura. [...] Isto foi abandonado, mas merece desenvolvimento. (BELEKIAN, 2011).

Para Pascale Lecoq, também são claras as diferenças entre o trabalho na UP6 e o LEM da escola: "A princípio, o LEM que era na UP6 era muito arquitetural. Eles analisavam as praças, as cidades, as casas; então eles trabalhavam sobre as paixões, eles trabalhavam sobre a casa do medo, a casa da inveja, eles faziam 
verdadeiramente, eles eram como os arquitetos. Quando passou para cá, se tornou mais próximo do teatro." (LECOQ, Pascale, 2011).

O LEM sempre funcionou no período noturno. Era nesse horário que a escola dispunha de seus espaços livres, uma vez que ela já oferecia os cursos de formação de atores nos turnos da manhã e da tarde. No princípio, as atividades de movimento corporal do LEM eram feitas na Grande Sala da escola, como até hoje, e as atividades de ateliê eram feitas no saguão, pois ainda não havia o ateliê localizado na rua do Faubourg Saint-Denis, n 55, ao lado da escola. Belekian relembrou esse período e a incorporação do novo espaço:

Na época, fazíamos o LEM no saguão e pouco a pouco ele foi ganhando corpo. De três alunos passamos para cinco, de cinco passamos a oito. Aqui [o ateliê onde funciona o LEM atualmente] era uma cristaleria. O Faubourg era conhecido por seus ateliês. Paris mudou. Antes havia as atividades artesanais. Aqui era uma cristaleria que eu conheci. Jacques me chamou e disse: 'Tem a cristaleria que está vazia, eles vão sair. A gente podia pegá-la para desenvolver o LEM'. Eu vim, nós visitamos juntos. Entramos! Aliás, as bacadas que estão lá no fundo são daquele tempo da cristaleria. (BELEKIAN, 2011).

Quando Lecoq se aposentou na UP6, ambos pensavam que Belekian iria continuar o trabaIho iniciado por Lecoq, uma vez que colaborava como seu assistente. Segundo Belekian, a política da escola mudou e já não havia o interesse anterior em orientar tanto o ensino em direção à cenografia e assim ele também não continuou na UP6 (BELEKIAN, 2011).

Krikor Belekian foi o mais longo colaborador de Jacques Lecoq. Foi seu aluno, orientando, assistente e também seu sócio. Se conhece- ram em 1969 e conviveram até o falecimento de Lecoq em 1999. Embora Lecoq tenha tido outros ex-alunos que se tornaram professores da escola por muito anos, Belekian é o que permaneceu por mais tempo vinculado à instituição (escola-APEM).

Belekian teve também um papel influente sobre Pascale Lecoq em sua escolha profissional. Pascale já havia cursado o LEM mais de uma vez no início dos anos de 1980 (tendo sido, portanto, aluna de Lecoq e Belekian). Considerando seu interesse por atividades manuais, pelo desenho, pelas artes aplicadas, a partir de conversas com Belekian sobre arquitetura, Pascale passou a se interessar pela área. Optou pela formação na UP6 justamente por ser uma instituição com uma visão bastante artística (LECOQ, Pascale, 2011).

Ela ingressou nessa instituição, formando-se como arquiteta em 1987. Lá foi novamente aluna de Jacques Lecoq, nas duas disciplinas por ele ministradas. Lecoq, por trabalhar lá, e Belekian, por ter ali estudado e seguido como assistente de Lecoq, conheciam de forma abrangente a UP6 e tiveram um papel importante na formação de Pascale:

Eu devo reconhecer que eles me deram o caminho, que me fizeram escoIher os professores que me convinham melhor. Então eu tenho um percurso um pouco especial na UP6, que era uma escola muito das artes plásticas. Então eu me encontrei fazendo os super cursos de filosofia, de escultura... e menos escolhas matemáticas, científicas. Fiz uma via muito plástica na UP6. Eu realmente fazia desenho, pegava todos os cursos de desenho que podia e menos os cursos técnicos. Eu fazia uma arquitetura um pouco particular ao fazer escultura, filosofia. A UP6 permitia isso, era uma escola genial. (LECOQ, Pascale, 2011). 
A partir de 1989, ela passou a fazer parte do quadro docente do LEM. Na época, havia uma aula de movimento que era dirigida por Lecoq e uma aula de construção realizada por Belekian. Pascale entrou com uma proposta entre os dois: a aplicação do curso de movimento de Lecoq ao desenho, assumindo assim uma terceira aula semanal, o ateliê livre, dando-se uma abordagem maior às artes plásticas. Assim ela foi colaborando na construção do LEM, propondo novas atividades:

o que era interessante é que eu fazia a relação entre meu pai e Krikor. Eram dois discursos muito diferentes. Eu estava entre os dois. Eu tentava explicar aos alunos que o que dizia meu pai e o que dizia Krikor era a mesma coisa. [...] Eu realmente estava em todas as aulas de Krikor, em todas as aulas de meu pai. Então, com isso, eu fazia a mistura. (LECOQ, Pascale, 2011).

Além das proposições de atividades plásticas, ela também foi assistente por vários anos nas aulas de movimento do LEM desenvolvidas por Jacques Lecoq, assumindo eventualmente algumas. Quando ele já se encontrava doente, ao final de sua vida, Pascale foi assumindo cada vez mais as aulas de movimento. Quando ele veio a falecer, em 1999, ela já havia assumido praticamente todas as aulas que a princípio eram dirigidas por ele. Após o falecimento, Pascale codirigiu o LEM juntamente com Belekian até 2011, quando este se aposentou após 35 anos dedicados a este laboratório de experimentação do espaço.

O LEM tem até hoje continuidade sob a direção de Pascale Lecoq contando com a colaboração de outros professores.

\section{Considerações finais}

Como visto, o que levou Lecoq a ingressar como docente na formação de arquitetos foram as reformas curriculares neste campo encaminhadas após as manifestações e protestos estudantis de 1968. Bosson foi quem mediou o convite, vislumbrando o potencial pedagógico de Lecoq que apoiava sua pedagogia em uma prática corporal investigativa. Neste afã, de repensar sistemas de ensino, dissolvendo fronteiras de conhecimento e empreendendo metodologias ativas, uma nova frente se desenvolveu repercutindo em dezenas de países, tantos quantos os alunos que passaram (e ainda passam) pelo LEM fundado por Lecoq e Belekian desde 1976.

Um tema interessante a ser aprofundado é sobre como se deu o processo de colaboração entre Jacques Bosson e Jacques Lecoq no âmbito da UP6. De que forma e profundidade um pode ter influenciado o trabalho do outro ainda não encontrei meios de saber, especialmente pela carência de produção bibliográfica de ambos.

O LEM como vimos, é resultante da pedagogia corporal de Lecoq, que envolve questões da educação física e do teatro, de princípios arquitetônicos e de artes plásticas (desenho, pintura, escultura) trazidos por Belekian e Pascale. Está baseado nos mesmo princípios pedagógicos empregados na formação de atores, ampliando estes princípios ao dialogar com outros campos de conhecimento e expressões humanas. A escola de arquitetura foi um âmbito no qual Lecoq pode ampliar sua pesquisa pessoal e a prática docente. As contribuições do LEM, do universo da arquitetura e das artes plásticas envoltos nele, ainda não foram significativamente analisados numa 
tentativa de perscrutar como isto tudo trouxe enriquecimento para a pedagogia lecoquiana na formação de atores, ao entrar em contato com outros universos criativos, reflexivos e práticos do âmbito da arquitetura, artes visuais e filosofia.

O presente artigo não esgota o tema. Ele busca apresentar contextos, funcionamentos e personagens, reconhecendo a existência deste aspecto da trajetória de Jacques Lecoq e indicando frentes de estudo que ampliem tanto a compreensão da ensino lecoquiano de formação de atores, como as práticas criativas no âmbito da arquitetura, da cenografia, das visualidades teatrais de forma mais ampla.

\section{Referências}

ALLARD, Sophie. Paysage de banlieue. 1987. 54f. Trabalho de diplomação (Graduação em Arquitetura). Unité pédagogique d'Architecture $n^{\circ}$ 6, École d'Architecture de Paris - La Villette, Paris, 1987.

CHARTE de l'école Charles-Dullin, 2011. Disponível em: <http://www.ecolecharlesdullin.fr/www/ chartemaj2011.pdf> Acesso em: 11 ago. 2011.

BELEKHIAN, Krikor. Spetacle d'architectures portables. 1972. 16 f. Trabalho de diplomação (Graduação em Arquitetura) - École d'Architecture de Paris La Vilette. Paris, 1972.

Entrevista a Ismael Scheffler com a participação de Antoine Blanchet na École International de Théâtre Jacques Lecoq. Paris, 14 de abr., 26 de maio. e 16 de jun. de 2011. 3 arquivos de Áudio do Windows Media (.WMA) (149 min.) Francês. Entrevista.
INTRODUCTION à un « Projet d'École ». École nationale supérieure d'architecture de Paris La Villette. Disponível em: <http://www.parislavillette.archi.fr/cms1.9.3/uploads/file/ecole\%20 presentation/projetensaplv.pdf> Acesso em: 20 ago. 2011.

LE FUR, Axelle. Recherche pour un habitat du calme. 1977. 41 f. Trabalho de diplomação (Graduação em Arquitetura). Unité Pédagogique d'Architecture $n^{\circ} 6$, École National Supérieure des Beaux-Arts, Paris, 1977.

LECOQ, Jacques. Le corps et son espace. Conférence-démonstration. In: Notes méthodologiques en architecture et en urbanisme - Semiotique de l'espace. n. 3-4, Centre M.M.I - Institut de l'Environnement, [Paris], jan. 1974, p. 273-281.

L.E.M. Mouvement et espace. Actualité de la Scénographie, n. 74, p. 48-49, 15 juin 1995.

O corpo poético: uma pedagogia da criação teatral. Trad.: Marcelo Gomes. São Paulo: SENAC São Paulo; SESC SP, 2010.

LECOQ, Pascale. Une gare et son quartier - les passions et états humains comme thème. 1987. 36 f. Trabalho de diplomação (Graduação em Arquitetura) - Unité pédagogique d'Architecture $n^{\circ}$ 6, École d'Architecture de Paris - La Villette, Paris, 1987.

. Entrevista a Ismael Scheffler com a participação de Antoine Blanchet na École International de Théâtre Jacques Lecoq. Paris, 12 de abr., 16 de maio de 2011. 3 arquivos de Áudio do Windows Media (.WMA) (85 min.) Francês. Entrevista. 
LÉVY, Stéphane. A corps perdu - Spatialisation du "corps" poétique dans l'œuvre de Bernard Noël: " Extraits du corps » (Partie Analytique). 1985. 111 f. Trabalho de diplomação (Graduação em Arquitetura). Unité pédagogique d'Architecture $n^{\circ} 6$, École d'Architecture de Paris - La Villette, Paris, 1985.

RISACHER, Marc-André. (org.) Jacques Bosson (1925-1984). Temoignage et souvenirs. In. : As - Actualité de la Scénographie [Jacques Bosson (1925-1984). Testemunhos e lembranças. I, n. 24, jul., ago., set. de 1984, p. 48-63.

RITORNO all'espressione fisica dell'attore. Atti della tavola rotonda Internazionale del 19 settembre 1969. La Biennale di Venezia, XXVIII Festival Internazional des Teatro di Prosa, 1969. Venezia: Nouva Editoriale, 11 settembre 1970.

RODRIGUEZ-VEGA, Severino. Corps-PI. 1985. 172 f. Trabalho de diplomação (Graduação em Arquitetura) - Unité pédagogique d'Architecture n ${ }^{\circ} 6$, École d'Architecture de Paris - La Villette, Paris, 1985.

SCHEFFLER, Ismael. O Laboratório de Estudo do Movimento e o percurso de formação de Jacques Lecoq. 2013. 591 f. Tese (Doutorado em Teatro) - Universidade do Estado de Santa Catarina, Programa de Pós-Graduação em Teatro, 2013.

O Laboratório de Estudo do Movimento da Escola Internacional de Teatro Jacques Lecoq. In: Anais do VII Congresso da Associação Brasileira de Pesquisa e Pós-Graduação em Artes Cênicas - ABRACE. Porto Alegre, 08 a 11 de outubro de 2012.
Disponível em: http://www.portalabrace.org/ viicongresso/completos/processos/Ismael_ SCHEFFLER__O_Laborat_rio_de_Estudo_ do_Movimento_da_Escola_Internacional_de_ Teatro_Jacques_Lecoq..pdf Acesso em: 06 jun 2018.

UNITÉ Pédagogique d'Architecture $n^{\circ} 6$. École d'Architecture de Paris La Vilette. Activités d'Enseignement 1981-1982. $4^{\circ}$ trimestre de 1981. $386 \mathrm{p}$.

Recebido: 30/10/2018

Aprovado: 31/12/2018 